\title{
Maternal Continuum of Care as Independent Determinant for Timely Initiation of Modern Contraceptive Methods Utilization among Postnatal Women in Arba Minch Zuria District, Southern Ethiopia
}

\section{Dereje Haile}

Reproductive and Nutrition Department, School of Public Health, College of Medicine and Health Science, Wolaita Sodo University, Southern Ethiopia

Correspondence should be addressed to Dereje Haile, derehaile2010@gmail.com

Received: June 22, 2021; Accepted: July 5, 2021; Published: July 11, 2020

\begin{abstract}
BACKGROUND

Initiation of family planning use during the postpartum period is crucial for both maternal and child health. Moreover, this period is the extension of maternal health care, and its level of uptake is built up on the level of continuum of care of maternal health care utilization. Continuum of maternal health care including antenatal care, skilled delivery and postnatal care is crucial for women's reproductive health. Despite that, there was no data regarding with the importance of continuum of care of maternal health care on the postpartum modern contraceptive utilization. Thus, the aim of this study was to assess the association of the continuum of maternal care on subsequent timely use of postpartum family planning.
\end{abstract}

\section{METHODS}

A community based cross sectional study was employed on 828 women. A multistage sampling technique was used to enroll the study participants. The data were collected by a semi-structured and pretested, face-to-face, interviewer administered questionnaire. Data were entered into EpiData 3.1 and analyzed by using SPSS 23 software. Bivariate and multivariable logistic regression analyses were used to declare the association between dependent and independent variables. Odds ratio, its $95 \%$ confidence interval (CI) and P-value <0.05 were used to determine the significance level.

\section{RESULTS}

The prevalence of timely initiation of postpartum contraceptive methods was $16.1 \%$. Having of postpartum care (AOR: 2.0(95\%CI: 1.2, 3.2)), completion of delivery level continuum of care (AOR: 2.9(95\%CI: 1.4, 6.1)), and completion of postnatal level continuum of care (AOR: 4.0(95\%CI: 2.0, 7.8)) were factors of timely intuition of postpartum contraceptive methods.

Citation: Dereje Haile, Maternal Continuum of Care as Independent Determinant for Timely Initiation of Modern Contraceptive Methods Utilization among Postnatal Women in Arba Minch Zuria District, Southern Ethiopia. J Med Biol4(1): 16-21. 
http://www.tridhascholars.org | December-2021

\section{CONCLUSION AND RECOMMENDATION}

The prevalence of timely initiation of postpartum contraceptive methods was low. The finding of this study implies that the need of strengthening the connection between maternal continuum of care and reproductive components of continuum of care.

\section{KEYWORDS}

Continuum of care; Postpartum; Contraception

\section{ABBREVIATIONS}

AOR: Adjusted Odds Ratio; ANC: Antenatal Care; CoC: Continuum of Care; MMR: Maternal Mortality Ratio

\section{INTRODUCTION}

Postpartum contraception is defined as women who have ever used any type of contraceptive method within one year after delivery [1]. Timely initiation (i.e., within six weeks of postpartum period) of contraceptive use after delivery is very important for both the health of mothers and their children. Moreover, this period is the extension of maternal health care, and its level of uptake is determined by the magnitude of completion of continuum of care of maternal health care utilization [2]. Continuum of maternal health care including antenatal care, skilled delivery and postnatal care is crucial for women's reproductive health. Despite that, there was no evidence regarding with the significance of continuum of care of maternal health care on the postpartum modern contraceptive utilization. Moreover, the association between specific components of continuum of care for maternal health (Antenatal care, skilled delivery, and postnatal care) and postpartum contraceptive utilization was well studied, but the association at composite level (Completion of Continuum of Care $(\mathrm{CoC})$ ) was not known. Thus, the aim of this study was to assess the association between completions of continuum of maternal health care and subsequent use of postpartum contraceptive use.

\section{MATERIALS AND METHOD}

\section{Study Setting}

The study was conducted in Arba Minch Zuria Woreda, Gamo zone, Southern Ethiopia, at $454 \mathrm{~km}$ South of Addis Ababa, the capital city of Ethiopia. The woreda has a total of 29 kebeles; two of which are semi-urban and the remaining 27 are rural. Of which 9 kebeles were selected randomly.

\section{Study Design}

A community based cross sectional study was applied from Dec 1-30/2020.

\section{Population}

All postnatal women in the district was considered as source population and all selected postnatal women in the randomly selected nine kebeles were study population.

\section{Sample Size Determination and Sampling Procedures}

A single population proportion formula was employed to calculate the sample size. The prevalence of postpartum modern contraceptive utilization was taken from study done in Arerosa (31.7\%) [3], and assuming 4\% error level and $95 \%$ confidence level. Sample size calculated for this study was 520. By multiplying 1.5 (design effect of 1.5), and adding non-response rate of $10 \%$, the final sample size was 858 . 


\section{Sampling Procedures}

This study used two stage procedures to enroll the study participants. First, of 29 kebeles, nine kebeles were selected randomly. Second, by using lists of women who gave birth, 828 postnatal women were selected by using systematic random sampling procedure. The lists of postnatal women were obtained from health posts in the selected kebeles and used as sampling frame.

\section{Data Collection and Techniques}

A semi-structured questionnaire which was adopted from Ethiopian Demographic and Health Survey (EDHS) and reviewing published literatures was used to collect the data [4]. Two public health officers and nine nurses were collected data through face-to-face interview. The questionnaire was prepared initially by English language and translated to local languages.

\section{Data Quality Assurance}

Before data collection, intensive two days training was provided to data collectors and supervisors. Pretesting was conducted on $5 \%$ of the total study population out of the study area and amendment was taken to the questionnaire.

\section{Data Analysis}

After data were cleaned, it was entered to EPI-data software version 3.1, and then exported to SPSS version 23 for analysis. Both the descriptive and inferential statistics was used in this study. In the descriptive statistics, frequency, and percentages were reported. Binary logistic regression model was used to identify factors associated with postpartum contraceptive utilization. In binary logistic regression, variables having a p-value $<0.25$ were selected as candidates for multivariable logistic regression analysis. In multivariable model, variables having p-value $<0.05$ were reported as significant and associated with the outcome variable.

\section{Operational Definition}

Timely postpartum contraceptive methods utilization: Using of modern contraceptive methods within 6 weeks of postpartum period. Completion of delivery level continuum of care for maternal health services: Having of antenatal care $>=4$ and skilled delivery [5].

Completion of postnatal level continuum of care for maternal health services: Having of $>=4 \mathrm{ANC}$ visit plus skilled delivery plus having of postnatal care [5].

\section{Full contents of antenatal care services}

Having of blood pressure measurement, weighing weight, testing blood sample, urine sample, iron provision, TT2+ vaccination, and health education on danger signs and nutrition [6].

\section{Ethics Approval and Consent to Participate}

Ethical approval was obtained from Institutional Research Ethics Review Board (IRB) of Arba Minch University, College of Medicine and Health Science (Ethical code of IRB/187/10). Following the approval, support letter to the concerned bodies was given from Post Graduate Coordination Office of Arba Minch University. Permission was obtained from Arba Minch Zuria district Health office. Then, informed, voluntary oral and written consent was also obtained from the study participants in accordance with Declaration of Helsinki.

\section{RESULTS}

Prevalence of Timely Postpartum Contraceptive Utilization among Postnatal Women

The overall prevalence of timely postpartum modern contraceptive utilization was 133 (16.1\%) (95\%CI: 13.619.1).

\section{Factors Affecting Timely Postpartum Modern Contraceptive Utilization}

In multivariate logistic regression, having of postnatal care, completion of delivery level continuum of care (ANC $>=4$ and skilled delivery) and completion of continuum of maternal care $(\mathrm{ANC}>=4+\mathrm{SD}+\mathrm{PNC})$ were associated with timely postpartum modern contraceptive utilization. 
The odds of utilizing timely modern contraceptive utilization were 2.0,2.9, and 4.0 times higher for women with having of postnatal care, attended $\mathrm{ANC}>=4$ and SD, and completes $\mathrm{CoC}$ for maternal care when compared to women's having no postnatal care, not having ANC4 and $\mathrm{SD}$, and not having of ANC4+SD +PNC.

\begin{tabular}{|c|c|c|c|c|c|c|}
\hline \multirow[t]{2}{*}{ Variables } & \multirow[t]{2}{*}{ Category } & \multicolumn{2}{|c|}{$\begin{array}{c}\text { Timely Postpartum Modern } \\
\text { Contraceptive Utilization }\end{array}$} & \multirow[t]{2}{*}{$\begin{array}{c}\text { P - } \\
\text { value }\end{array}$} & \multirow[t]{2}{*}{$\begin{array}{c}\text { COR } \\
(95 \% \mathrm{CI})\end{array}$} & \multirow[t]{2}{*}{$\begin{array}{c}\text { AOR } \\
(95 \% \mathrm{CI})\end{array}$} \\
\hline & & No & Yes & & & \\
\hline \multirow{2}{*}{$\begin{array}{c}\text { Pre-Pregnancy } \\
\text { Contraceptive Utilization }\end{array}$} & No & 233(88.6) & $30(11.4)$ & & 1 & 1 \\
\hline & Yes & $462(81.8)$ & $103(18.2)$ & 0.014 & $1.7(1.1,2.7)$ & $1.2(0.7,1.9)$ \\
\hline \multirow[t]{2}{*}{ Preparedness for Birth } & $\begin{array}{l}\text { Not Well } \\
\text { Prepared }\end{array}$ & $500(85.2)$ & $87(14.8)$ & & 1 & 1 \\
\hline & $\begin{array}{c}\text { Well } \\
\text { Prepared }\end{array}$ & 195(80.9) & $46(19.1)$ & 0.130 & $1.4(0.9,2.0)$ & $1.1(0.6,1.5)$ \\
\hline \multirow[t]{2}{*}{ Antenatal Care Visits } & $1-3$ & 539(86.5) & $84(13.5)$ & & 1 & 1 \\
\hline & $>=4$ & $156(76.1)$ & $49(23.9)$ & 0.001 & $2.0(1.4,3.0)$ & $0.5(0.3,1.2)$ \\
\hline \multirow[t]{2}{*}{ Time for ANC Visit } & $\begin{array}{l}\text { At or Above } \\
16 \text { Weeks }\end{array}$ & $544(85.4)$ & $93(14.6)$ & & 1 & 1 \\
\hline & $<16$ Weeks & 151(79.1) & $40(20.9)$ & 0.037 & $1.5(1.1,2.3)$ & $1.1(0.6,1.6)$ \\
\hline \multirow[t]{2}{*}{ Contents of ANC } & $\begin{array}{l}\text { Partially } \\
\text { Utilized }\end{array}$ & $576(84.3)$ & $107(15.7)$ & & 1 & \\
\hline & $\begin{array}{c}\text { Fully } \\
\text { Utilized }\end{array}$ & $120(82.2)$ & $26(17.8)$ & 0.527 & $1.2(0.7,1.9)$ & \\
\hline \multirow[t]{2}{*}{ Place for Delivery } & $\begin{array}{c}\text { Health } \\
\text { Faculties }\end{array}$ & $307(78.7)$ & $83(21.3)$ & $<0.001$ & $2.0(1.4,3.1)$ & $0.9(0.6,1.5)$ \\
\hline & Home & $388(88.6)$ & $50(11.4)$ & & 1 & 1 \\
\hline \multirow[t]{2}{*}{ Postnatal Care } & No & $528(88)$ & $72(12)$ & & 1 & 1 \\
\hline & Yes & $167(73.2)$ & $61(26.8)$ & $<0.001$ & $2.7(1.8,3.9)$ & $2.0(1.2,3.2)$ \\
\hline \multirow{2}{*}{$\begin{array}{c}\text { Completion of } \mathrm{ANC}>=4 \\
\text { Visits and Skilled Delivery }\end{array}$} & No & $577(88.6)$ & $74(11.4)$ & & 1 & 1 \\
\hline & Yes & $118(66.7)$ & $59(33.3)$ & $<0.001$ & $3.9(2.6,5.8)$ & $2.9(1.4,6.1)$ \\
\hline \multirow{2}{*}{$\begin{array}{l}\text { Completion of Continuum of } \\
\text { Care (ANC>=4+SD+PNC) }\end{array}$} & No & $658(87.9)$ & $91(12.1)$ & & 1 & \\
\hline & Yes & $37(46.8)$ & $42(53.2)$ & $<0.001$ & $8.2(5.1,13.4)$ & $4.0(2.0,7.8)$ \\
\hline
\end{tabular}

Table 1: Factors affecting timely postpartum modern contraceptive utilization among postnatal women's in Wolaita Zone. ANC: Antenatal Care; SD: Skilled Delivery; PNC: Postnatal Care; CI: Confidence Interval; OR: Odds Ratio; AOR: Adjusted Odds Ratio; 1: Reference Category

\section{DISCUSSION}

The overall prevalence of timely postpartum contraceptive utilization among postnatal women was $16.1 \%$.
Having of postnatal care, completion of delivery level $\mathrm{CoC}$, and completion of postnatal level $\mathrm{CoC}$ was predictors of IPP contraceptive utilization. 
The overall prevalence $16.1 \%$ was lower than the study done in Aroressa district, Southern Ethiopia (31.7\%) [3]. This variation might be due to difference in the study population. The former study recruits study participants as women who gave birth the last 12 months while the later one includes women who gave birth the last 6 months. This might decrease the recall bias regarding with utilization of postpartum contraceptive methods.

The odds of timely initiation of postpartum contraceptive utilization were 2.9 times higher for women who attends ANC four and above and have Skilled delivery at health facilities when compared to their counterparts. This finding implies that the concerned bodies should gave attention to the dropout rate of ANC to skilled delivery in turn to increase the uptake of postpartum contraceptive utilization [7].

The odds of timely utilization of postpartum contraceptive methods were 4 times higher for women who completed continuum of care for maternal health when compared to their counterparts. This finding was in line with study done in Nepal [2]. This implies that the need for strengthening the integration of reproductive and maternal components of continuum of care (RMNCH).

\section{DATA SHARING STATEMENT}

The data used to support the findings of this study are available from the corresponding author upon request via email address of derehaile2010@gmail.com.

\section{ACKNOWLEDGMENT}

We would like to thank Arba Minch University, the College of Health Sciences, and the Department of Public Health and we will also extend our thanks to the Arba Minch Zuria district health staff as well as the data collectors for their contribution in facilitating the conduct of this research.

\section{AUTHOR CONTRIBUTIONS}

The author made a significant contribution to the work reported, whether that is in the conception, study design, execution, acquisition of data, analysis and interpretation, or in all these areas; took part in drafting, revising or critically reviewing the article; gave final approval of the version to be published; have agreed on the journal to which the article has been submitted; and agree to be accountable for all aspects of the work.

\section{FUNDING}

There is no funding to report.

\section{CONFLICT OF INTEREST}

All authors declare that there is no conflict of interest both in financial and non-financial interests.

\section{REFERENCES}

1. World Health Organization (2013) Programming strategies for postpartum family planning.

2. Kafle RB, Dulal KP, Pandey KP (2017) Continuum of maternal health care and the use of postpartum family planning in Nepal. ICF: 133.

3. Dona A, Abera M, Alemu T, et al. (2018) Timely initiation of postpartum contraceptive utilization and associated factors among women of child bearing age in Aroressa District, Southern Ethiopia: A community based cross-sectional study. BMC Public Health 18(1): 1-9.

4. (2016) ICF CSACE(a), Ethiopia demographic and health survey 2016: Key Indicators Report.

5. Hamed A, Mohamed E, Sabry M (2018) Egyptian status of continuum of care for maternal, newborn, and child health: Sohag Governorate as an example. International Journal of Medical Science and Public Health 7(6): 1. 
http://www.tridhascholars.org | December-2021

6. Islam MM, Masud MS (2018) Determinants of frequency and contents of antenatal care visits in Bangladesh: Assessing the extent of compliance with the WHO recommendations. PloS One 13(9): e0204752.

7. McDougal L, Rusch ML, Silverman JG, et al. (2016) Linkages within the reproductive and maternal health continuum of care in Bangladesh. Asia Pacific Journal of Public Health 28(5): 423-437. 